\title{
Honoré de Balzac, Ferragus, La Fille aux yeux d'or
}

\section{Patrick Berthier}

\section{(2) OpenEdition}

\section{Journals}

\section{Édition électronique}

URL : http://journals.openedition.org/studifrancesi/1383

DOI : ERREUR PDO dans /localdata/www-bin/Core/Core/Db/Db.class.php L.34 : SQLSTATE[HYO00]

[2006] MySQL server has gone away

ISSN : 2421-5856

\section{Éditeur}

Rosenberg \& Sellier

\section{Édition imprimée}

Date de publication : 1 décembre 2015

Pagination : 606

ISSN : 0039-2944

\section{Référence électronique}

Patrick Berthier, «Honoré de Balzac, Ferragus, La Fille aux yeux d'or », Studi Francesi [En ligne], 177 (LIX I III) | 2015, mis en ligne le 01 décembre 2015, consulté le 08 janvier 2021. URL : http:// journals.openedition.org/studifrancesi/1383 ; DOI : https://doi.org/ERREUR PDO dans /localdata/ www-bin/Core/Core/Db/Db.class.php L.34 : SQLSTATE[HY000] [2006] MySQL server has gone away

Ce document a été généré automatiquement le 8 janvier 2021.

\section{c) (i) $९$}

Studi Francesi è distribuita con Licenza Creative Commons Attribuzione - Non commerciale - Non opere derivate 4.0 Internazionale. 


\title{
Honoré de Balzac, Ferragus, La Fille aux yeux d'or
}

\author{
Patrick Berthier
}

\section{RÉFÉRENCE}

HONORÉ DE BALZAC, Ferragus, La Fille aux yeux d'or, présentation, notes, annexes et bibliographie mises à jour par Michel LICHTLÉ, Paris, Flammarion, 2014, «GF», [1988], pp. 338.

1 L'édition de l'Histoire des Treize par Michel Lichtlé a été reçue dès sa première mise en vente, en 1988, comme un travail de haute qualité, auquel on ne pouvait guère reprocher qu'un défaut dont l'éditeur était innocent: le choix, purement commercial, de publier séparément La Duchesse de Langeais. La direction de GF s'est obstinée dans ce choix en publiant, en 2008, une mise à jour de la seule Duchesse, dans le sillage du film de Rivette, Ne touchez pas la hache, sorti l'année précédente.

Voici aujourd'hui une version toilettée de l'autre volume, qui réunit le premier et le troisième épisode de l'Histoire, et qui s'ouvre de façon à la fois indiscrète et déplaisante sur un entretien avec l'écrivain et traducteur Claro (pp. 7-15); la volonté de séduire un public "djeune" est la seule justification de cet ajout bien inutile, dont Michel Lichtlé est naturellement innocent.

Oublions vite ces huit pages pour relire (pp. 17-67) sa magnifique «présentation» de l'ensemble désarticulé que forment ces deux épisodes privés de leur fleuron central. Il y avait un défi à relever dans la nécessité de parler à la fois de l'œuvre telle que Balzac l'a voulue, écrite et éditée, et des deux seuls morceaux conservés pour ce volume GF; nous pouvons constater qu'aujourd'hui comme naguère, la gageure est brillamment tenue. La caractérisation analytique des personnages, de l'ancien bagnard Ferragus à de Marsay le cynique, en passant par les femmes, touchantes (Mme Jules menée à la mort par trop de dévouement) ou effrayantes (la marquise de San-Réal meurtrière par trop de passion), est de même qualité que les vues plus générales sur le Paris de Balzac ou 
sur ses convictions systématiques; il est clairement dit aussi que si les trois romans dont nous lisons ici les premier et dernier forment un magistral ensemble, c'est plus par la description également forte des passions qui habite chacun d'eux, que par cette fameuse société des "Treize», qui peine à exister autrement que comme une simple armature (ce qui, bien sûr, ne suffit pas à justifier qu'on ait ainsi démembré l'œuvre). Les deux «Notices» (pp.311-323) apportent, en complément de cette vaste entrée en lecture, tous les renseignements génétiques désirables. La «Chronologie» (pp. 324-333) est toujours aussi précise, et la «Bibliographie» (pp. 334-337) accueille de nombreuses entrées postérieures à la date de la première édition du volume. L'annotation placée en bas de pages est mesurée, mais efficace, et l'édition matérielle du volume est pratiquement sans défaut, ce qui mérite d'être signalé avec insistance en un temps où on fait payer cher aux lecteurs tant de travaux imprimés en dépit du bon sens. Une heureuse réédition, qu'il fallait accueillir comme elle le mérite. À quand, chez GF, la nécessaire refonte de deux volumes en un seul, qui rendrait enfin justice à la vraie Histoire des Treize de Balzac? 